\title{
Human capital in Spain and its distribution by provinces (1964-2013)
}

\author{
Lorenzo Serrano ${ }^{1}$, Ángel Soler ${ }^{2}$ \\ ${ }^{1}$ Universitat de València and Ivie, València, Spain (email: lorenzo.serrano@ivie.es) \\ ${ }^{2}$ Universitat de València and Ivie, València, Spain (email: angel.soler@ivie.es)
}

Received: 2 April 2015/Accepted: 2 April 2015

\section{Description of the resource}

Since 1994, the Bancaja Foundation and the Ivie have been conducting an extensive research program on human capital measurements in Spain. The regularly updated Ivie database "Human Capital in Spain and its distribution by provinces" is the basis of this program, providing information on the accumulation of human capital in Spain over the last five decades.

The human capital estimates included in this database contain a wide range of information on how education levels in Spain have evolved. Classification is according to the level of studies completed and other human capital indicators. The database includes information for up to the second trimester of 2013. The Human Capital Series includes data at the national level covering the period 1964-2013, as well as provincial (NUTS3) and autonomous community (NUTS2) data covering the period 1977-2013 according to the 17 Spanish autonomous communities, 2 autonomous cities (Ceuta and Melilla) and 50 provinces.

These series present the evolution of the working-age population in relation to occupation by level of education completed. Data are provided for working-age population, economically active population, employed population, and unemployed population. Series for the period 1964-2013 distinguish five levels of education. For the 1977-2013 series, eight levels of education are distinguished. Data on average years of schooling are also available.

Employment data are provided according to branches of activity and levels of education. At both the national and provincial/autonomous communities level, six industries are considered: Agriculture, energy, industry, construction, market services, and non-market services. Total services data are also provided.

The database also includes human capital indicators based on personal characteristics (age, sex, level of education) and the differences in wages associated with them ${ }^{1}$. These "economic value of human capital" indicators are provided for the period 1977-2013 for working-age population, economically active population, and total employment. In all cases, data are disaggregated at the provincial and autonomous communities level. These indicators are expressed in terms of the number of equivalent male workers less than 20 years old and with no schooling or only primary schooling (ISCED 1 or less).

Finally, data on foreign working-age population and long-term unemployment, grouped by eight levels of education, for the period 2000-2013 are provided at autonomous

\footnotetext{
${ }^{1}$ Full details of the methodological criteria followed can be found in Metodología para la Estimación de las series de Capital Humano 1964-2013.
} 


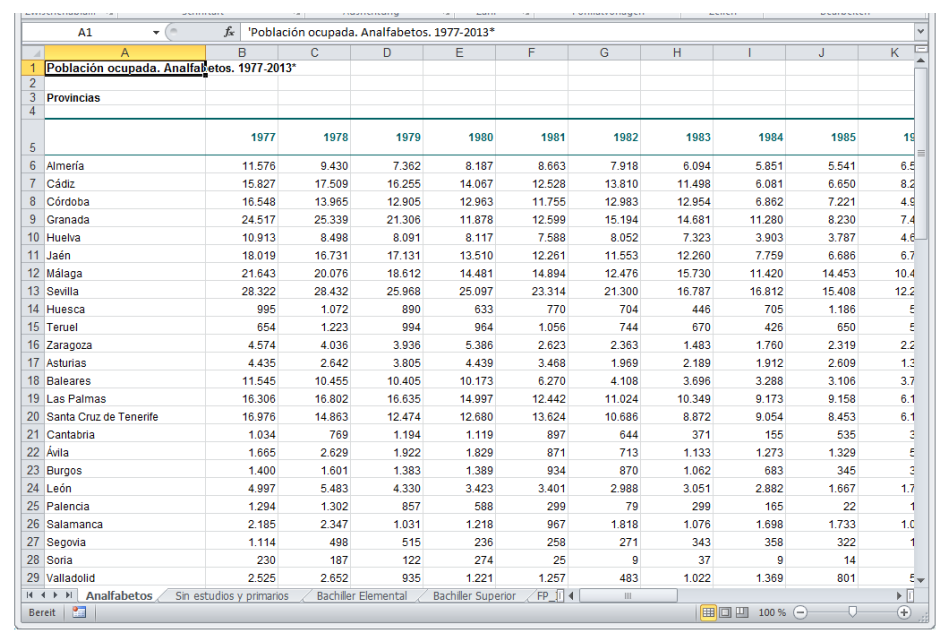

Figure 1: An example of the data available

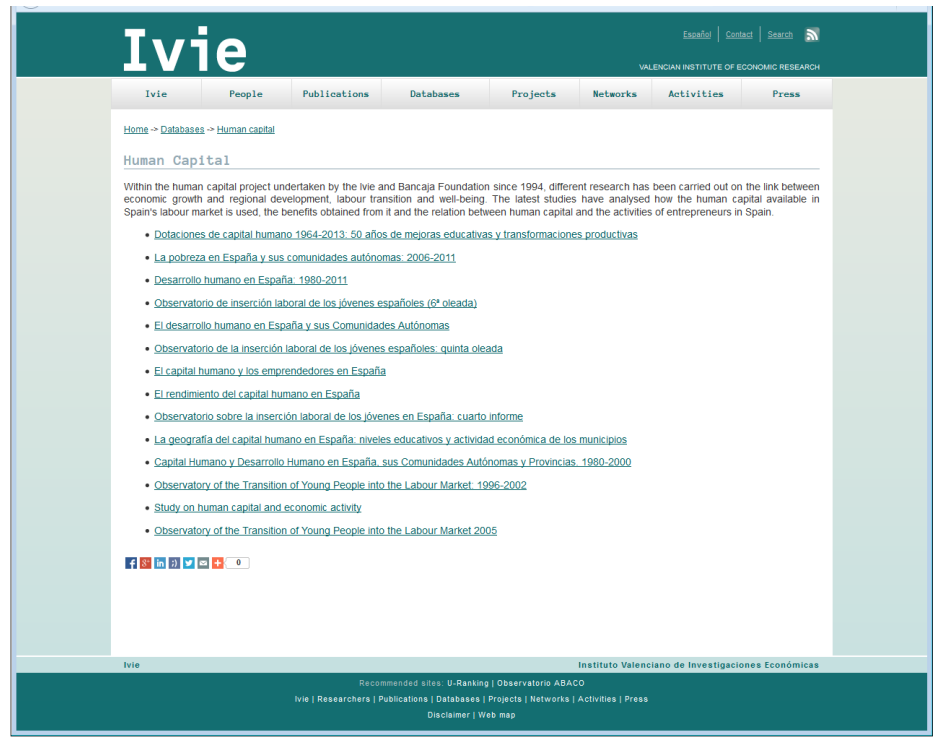

Figure 2: List of the studies available on the web page

communities level. This extensive database, which the Bancaja Foundation and the Ivie have made available to the public, is accompanied by various studies examining the link between human capital and economic growth, regional development, labor market issues and well-being, and also by a number of Human Capital Notes, which summarize the main results obtained in the project ${ }^{2}$. The next database release, which will cover up to 2015, is expected to be published by the second half of 2015 .

\section{Resource links}

- Database: http://www.ivie.es/en/banco/caphum/series.php

- Studies: http://www.ivie.es/en/banco/caphum/estudios.php

- Human Capital Notes: http://www.ivie.es/en/pub/div/cch/cch.php

\footnotetext{
${ }^{2}$ Available in Spanish at http://www.ivie.es/en/banco/caphum/caphum.php
} 